\title{
PROMOÇÃO DA SAÚDE E TERAPIA COMUNITÁRIA INTEGRATIVA: POR UMA VISÃO HOLÍSTICA SOBRE O CUIDADO EM SAÚDE NA PERSPECTIVA DOS RECURSOS EDUCACIONAIS
}

\author{
HEALTH PROMOTION AND INTEGRATIVE COMMUNITY THERAPY: \\ FOR AHOLISTIC VIEW OF HEALTH CARE FROM THE PERSPECTIVE \\ OF EDUCATIONALRESOURCES
}

Lauriane Martins Santana ${ }^{1}$

Sheila Soares de Assis ${ }^{2}$

Tania Cremonini de Araujo Jorge ${ }^{3}$

RESUMO: OBJETIVO: Identificar os pontos de convergência entre a promoção da saúde e a $\mathrm{TCl}$ através do emprego das técnicas de análise documental descritiva e análise textual discursiva (ATD) aos recursos educacionais empregados na prática de formação dos terapeutas comunitários. METODOLOGIA: Trata-se de uma pesquisa qualitativa na qual utilizamos as técnicas Análise Documental Descritiva (ADD) e Análise Textual Discursiva (ATD). RESULTADOS: Apontaram que os materiais repercutem sobre a coparticipação da comunidade para a efetivação das ações de promoção da saúde, valorizando-se os saberes populares e científicos; encorajamento da construção de redes de apoio social e a intersetorialidade nos territórios evidenciaram-se como estratégias para a consolidação da $\mathrm{TCl}$ no cuidado a saúde mental; concepções holística, transdisciplinar e transcultural norteiam a compreensão sobre o processo saúde doença, orientando o pensar e agir dos profissionais de saúde. CONCLUSÃO: A TCl apresentou-se como prática de aprendizagem coletiva mediada por partilhas e vivências teórico-práticas. Consideramos que a os pressupostos teórico-metodológicos da $\mathrm{TCl}$ encontram-se fortemente alinhados às discussões presentes no campo da promoção da saúde. Torna-se fundamental uma constante atualização dos recursos educacionais em

\footnotetext{
${ }^{1}$ Psicóloga. Mestranda do Programa de Pós Graduação em Ensino em Biociências e Saúde Laboratório de Inovações em Terapias, Ensino e Bioprodutos - Instituto Oswaldo Cruz/Fundação Oswaldo Cruz (FIOCRUZ).

${ }^{2}$ Bióloga. Doutora em Ensino em Biociências e Saúde e Pesquisadora do Laboratório de Inovações em Terapias,Ensino e Bioprodutos - Instituto Oswaldo Cruz/Fundação Oswaldo Cruz (FIOCRUZ).

${ }^{3}$ Médica. Doutora em Ciências pela Universidade Federal do Rio de Janeiro (UFRJ), Pesquisadora Titular em Saúde Pública da Fundação Oswaldo Cruz - Laboratório de Inovações em Terapias, Ensino e Bioprodutos - Instituto Oswaldo Cruz/Fundação Oswaldo Cruz (FIOCRUZ).
} 
função das mudanças recorrentes no âmbito das políticas públicas e no contexto sócio-histórico, cultural e econômico do país, visto que influenciam na atuação profissional e, consequentemente, nas ações de saúde ofertadas à população.

Palavras chave: Integralidade em saúde. Materiais de Ensino. Saúde Mental.

\begin{abstract}
OBJECTIVE: To identify the points of convergence between health promotion and ICT through the use of techniques of descriptive document analysis and textual discursive analysis (ATD) to the educational resources used in the training of community therapists. METHODOLOGY: This is a qualitative research in which we use the techniques Descriptive Document Analysis (ADD) and Textual Discursive Analysis (ATD). RESULTS: They pointed out that the materials have an impact on the co-participation of the community in order to carry out health promotion actions, valuing popular and scientific knowledge; encouraging the construction of social support networks and intersectoriality in the territories were highlighted as strategies for the consolidation of ICT in mental health care; holistic, transdisciplinary and cross-cultural conceptions guide the understanding of the health-disease process, guiding the thinking and acting of health professionals. CONCLUSION: TCI presented itself as a collective learning practice mediated by sharing and theoreticalpractical experiences. We believe that the theoretical and methodological assumptions of the $\mathrm{TCl}$ are strongly aligned with the discussions present in the field of health promotion. It is essential to constantly update educational resources due to recurring changes in the scope of public policies and in the socio-historical, cultural and economic context of the country, since they influence professional performance and, consequently, the health actions offered to the population.
\end{abstract}

Keywords: Comprehensiveness in health. Teaching Materials. Mental health. 


\section{INTRODUÇÃO}

A Política Nacional de Promoção da Saúde (PNPS) define que a promoção da saúde consiste na criação e implementação de estratégias e ações de saúde que visem a consolidaçãode práticas de cuidado com enfoque na saúde da população e na melhora da qualidade de vida de indivíduos, grupos e coletividades buscando assegurar o acesso aos serviços de saúde de forma universal, equânime e integral (BRASIL, 2017).

O campo é atravessado por tensões que produzem discursos com interesses divergentes, visto que textos dos documentos oficiais de organizações governamentais e de conferências nacionais e internacionais sobre a promoção da saúde, não necessariamente expressam seu conteúdo de forma crítica. Geralmente há uma visão reducionista sobre os determinantes sociais da saúde (DSS), tomandoos como algo que está sob o controle individual, no entanto o processo saúdedoença, as desigualdades sociais e a necessária responsabilização dos governos para a implementação das ações de saúde são vistas como questões interligadas. (CORREIA e MEDEIROS, 2014).

A comparação conceitual entre os DSS e a Determinação Social da Saúde, proveniente das discussões acadêmicas da medicina social latino-americana, do movimento de reforma sanitária brasileira (MRSB) e do movimento de promoção da saúde do Canadá, analisa que a primeira adota uma visão restritiva e fragmentada dos fatores, contextos e circunstâncias de uma realidade, encobrindo a compreensão sobre aspectos multidimensionais que abrangem o processo saúdedoença. $\mathrm{Na}$ segunda, amplia-se $\mathrm{o}$ entendimento sobre esse processo estabelecendo-se conexões entre o momento histórico da sociedade, o regime de acumulação do capital e seus modos de produção e reprodução e, a história de vida social dos indivíduos (GARBOIS, SODRÉ e DALBELLO-ARAUJO 2017; ROCHA e DAVID 2015). 
É necessária a diferenciação entre os termos prevenção e promoção da saúde, visto que o primeiro diz respeito as ações de controle de riscos e agravos das doenças, buscando a reduçãoda incidência e prevalência das doenças e, a segunda refere-se a mudanças das condições de vida e trabalho, envolvendo questões de ordem social, psicológica, ambiental, econômica etc. Nesse sentido, o agir em saúde suscita uma permeabilidade e transversalidade entre esses discursos, visando novas e diferentes formas de compreensão de um fenômeno, ou seja, o fazer em saúde enquanto conhecimento científico deveria lançar-se ao desafio de transitar pelas dimensões da objetividade e da subjetividade (CZERESNIA, 2009).

Em uma perspectiva histórica sobre a promoção da saúde e qualidade de vida nos últimos 40 anos, Buss et al (2020) enfocam na discussão sobre esses conceitos e suas estratégias de operacionalização através das políticas públicas saudáveis viabilizadas por meio da intersetorialidade e da nova institucionalidade social. Essa última refere-se à materialidade de propostas de saúde nas políticas de forma geral, nos municípios saudáveis, na Agenda 2030 e nos Objetivos de Desenvolvimento Sustentável (ODS). Os autores assinalam que o conceito contemporâneo de promoção da saúde abordado na Carta de Ottawa, onde são descritos um conjunto de valores relacionados a solidariedade, democracia, participação, parceria, cidadania entre outros e, inclusive, a articulação entre Estado, comunidade, indivíduos, sistemas de saúdee parcerias institucionais visando a responsabilidade coletiva para a saúde de todos. Em suma, a Carta de Ottawa preconiza que a saúde está para além do setor da saúde, pois contempla um conjunto de ações que contribuem para a equidade em saúde, distribuição de renda e políticas sociais (CARTA DE OTTAWA, 1986).

Tendo em vista que os trabalhadores de saúde são agentes protagonistas nesse processo, e cuidam de pessoas na gestão do trabalho, faz-se necessário que adquiram habilidades e competências para o desenvolvimento de ações de saúde (MOYSÉS et al, 2018). Portanto, é urgente investigar o contexto de sua formação e seu alinhamento com uma perspectiva ampliadade saúde e, consequentemente, com a promoção da saúde.

Assim, nos propusemos a seguinte questão: Qual o ponto de partida para uma discussão que nos possibilite dialogar sobre a promoção da saúde articulada às 
práticas de cuidado em saúde no âmbito da formação do terapeuta comunitário e de seus formadores? Nossas indagações nos direcionaram à Terapia Comunitária Integrativa ( $\mathrm{TCl}$ ), pois partimos dopressuposto de que a prática traz em si elementos que dialogam com a PNPS.

\section{Terapia Comunitária Integrativa (TCI)}

Criada no Brasil em 1987 na comunidade de Pirambu em Fortaleza - CE, pelo professor Adalberto Barreto da Universidade Federal do Ceará (UFC). A TCl é um espaço de encontros interpessoais e comunitários que visa promover a construção de vínculos, o acolhimento, a troca de experiências, buscando fortalecer os recursos individuais e da comunidade para a resolução dos problemas (BARRETO, 2010; GOMES, 2013). Naquela época existia uma grande demanda de pessoas da comunidade que procuravam pelo ambulatório de psiquiatria da UFC em busca de psicofármacos para a eliminação de sintomas depressivos ou episódios de crise psiquiátrica. Assim, o professor e os estudantes iniciaram um trabalho direcionado à escuta acolhedora aos moradores na comunidade, criando o Movimento Integrado de Saúde Mental Comunitária (MISMEC) e posteriormente a TCI (BARRETO, 2010; GOMES, 2013).

Tendo em vista o contexto vivido pela comunidade, atravessado por processos de exclusão social, êxodo rural, segregação, desigualdades socioeconômicas, revoltas e lutas de movimentos sociais pela reivindicação de direitos a TCl surge como campo de desenvolvimento de ações de saúde comunitária (GOMES 2013; BARRETO, 2010; GIFFONI, 2008). Atualmente, a TCl é uma prática integrativa e complementar inclusa na Política Nacional de Práticas Integrativas e Complementares (PNPIC) do SUS pela portaria nº 849 de 27 de março de 2017.

É importante ressaltar que a $\mathrm{TCl}$ só pode ser desenvolvida por terapeutas comunitários que realizaram o curso de formação em polos credenciados pela Associação Brasileira de Terapia Comunitária (ABRATECOM). O presente estudo tem como objetivo identificar as relações de convergência entre a TCl e Promoção 
da Saúde através da análise dos materiais educativos que subsidiam a formação de terapeutas comunitários.

\section{METODOLOGIA}

Trata-se de uma pesquisa qualitativa na qual utilizamos as técnicas Análise DocumentalDescritiva (ADD) e Análise Textual Discursiva (ATD). A primeira consiste na operacionalização do conteúdo das informações contidas em documentos, servindo de base para a complementação e contextualização de dados para a pesquisa. A partir de uma representaçãocondensada das informações, a consulta e armazenagem são viabilizadas, facilitando o acesso ao observador. (SOUZA; KANTORSKI; VILLAR LUIS, 2011). A segunda se refere a uma análise de informações textuais que tem como objetivo propor, a partir de uma perspectiva hermenêutica, novas compreensões e interpretações sobre os discursos e fenômenos estudados.(MORAES e GALIAZZI, 2016).

Para a coleta de dados selecionamos 3 livros, 1 agenda e 1 cartilha que são utilizados em $\mathrm{TCl}$ na formação e qualificação, como recurso de apoio e para regulamentação organizacional. Efetuamos um processo de unitarização das informações que foram transformadas em unidades de análise, através da seleção de figuras e fragmentos dos textos contidos no corpus do estudo. Por meio de leitura atenta e aprofundada do material, focando nos conceitos-chave, buscamos identificar a correspondência entre as ilustrações e o conteúdo textual com a temática da promoção da saúde para a categorização e interpretação dos dados.

Nesse sentido, apresentamos informações relativas ao material analisado conforme mostra o quadro 1: 
Quadro 1: Material didático e organizacional analisado.

\begin{tabular}{|c|c|c|c|c|c|c|c|}
\hline$\underset{\text { Material }}{\text { ID }}$ & Tipo $^{1}$ & Título & Autor & $\begin{array}{c}\text { Ano de } \\
\text { Publicação }\end{array}$ & $\begin{array}{c}N^{\circ} \text { de } \\
\text { páginas }\end{array}$ & Público & Objetivo \\
\hline A & Livro & $\begin{array}{c}\text { Terapia } \\
\text { Comunitária } \\
\text { passo a } \\
\text { passo }\end{array}$ & $\begin{array}{c}\text { Adalberto } \\
\text { Barreto }\end{array}$ & 2010 & 408 & $\begin{array}{c}\text { Terapeutas } \\
\text { Comunitários }\end{array}$ & $\begin{array}{l}\text { Livro de referência } \\
\text { paracurso de } \\
\text { capacitação em } \\
\text { TCl }\end{array}$ \\
\hline B & Livro & \begin{tabular}{|} 
Cuidando do \\
Cuidador: \\
Técnicas e \\
vivências \\
para o \\
resgate da \\
autoestima
\end{tabular} & $\begin{array}{c}\text { Adalberto } \\
\text { Barreto }\end{array}$ & 2017 & 228 & $\begin{array}{c}\text { Formadores } \\
\text { em TCl }\end{array}$ & $\begin{array}{c}\text { Livro de referência } \\
\text { do curso Cuide de } \\
\text { si e resgate sua } \\
\text { autoestima }\end{array}$ \\
\hline C & Livro & \begin{tabular}{|} 
Quando a \\
boca cala os \\
órgãos \\
falam... \\
Desvendando \\
as \\
mensagens \\
dos sintomas
\end{tabular} & $\begin{array}{c}\text { Adalberto } \\
\text { Barreto }\end{array}$ & 2014 & 400 & $\begin{array}{c}\text { Terapeutas } \\
\text { Comunitários } \\
\text { e formadores }\end{array}$ & $\begin{array}{c}\text { Livro } \\
\text { complementar } \\
\text { para } \\
\text { aprofundamento }^{2}\end{array}$ \\
\hline D & Agenda & $\begin{array}{c}\text { A fala do } \\
\text { sintoma: } \\
\text { Desvende a } \\
\text { mensagem } \\
\text { dos sintomas }\end{array}$ & $\begin{array}{c}\text { Adalberto } \\
\text { Barreto }\end{array}$ & 2019 & 136 & $\begin{array}{c}\text { Terapeutas } \\
\text { Comunitários } \\
\text { e formadores }\end{array}$ & $\begin{array}{c}\text { Agenda/fichas } \\
\text { complementares } \\
\text { para } \\
\text { aprofundamento }\end{array}$ \\
\hline E & Cartilha & \begin{tabular}{|c|} 
Caderno \\
Orientadorn \\
$2-$ \\
Capacitação \\
em TCl e \\
Técnicas de \\
Resgate da \\
Autoestima
\end{tabular} & $\begin{array}{c}\text { Maria da } \\
\text { Graça } \\
\text { Pedrazzi } \\
\text { Martini, } \\
\text { Maria } \\
\text { Lucia de } \\
\text { Andrade } \\
\text { Reis }\end{array}$ & 2019 & 52 & $\begin{array}{c}\text { Formadores } \\
\mathrm{em} \mathrm{TCl}\end{array}$ & $\begin{array}{c}\text { Cartilha de } \\
\text { consulta para } \\
\text { organização de } \\
\text { capacitações }\end{array}$ \\
\hline
\end{tabular}

Livro sm: 1. Conjunto de folhas de papel, impressas ou manuscritas, coladas ou costuradas num dos lados, cobertas por uma capa; 2. Esse mesmo livro, considerando-se o seu conteúdo, geralmente de caráter literário, artístico, científico, técnico etc., constituído por um ou mais volumes; 3. Cada um dos volumes que constituem uma determinada obra.

\footnotetext{
${ }^{1}$ Apresentamos o significado dos tipos de material, de acordo com o dicionário online Michaelis:

${ }^{2}$ O nome do curso foi alterado em 2020. Antes era denominado como "Cuidando do cuidador".
} 
Agenda sf 1. Livro ou caderno datado em que se anotam, dia a dia, os compromissos, anotações pessoais etc.; 2. Compromissos a serem cumpridos por alguém; 3. Lista de assuntos a serem discutidos em reuniões, conferências, congressos etc.

Cartilha sf: 1. Livro em que se aprende a ler, carta de á-bê-cê; 2. Tratado elementar de qualquer matéria.

Fonte: Produzida pela autora.

\section{Resultados e Discussão}

A partir da análise do material coletado, as informações foram agrupadas e alocadas em cinco categorias. A seguir, apresentamos o quadro 2 que mostra suas denominações e descrições:

Quadro 2. Temas abordados pelos materiais consultados.

\begin{tabular}{|l|l|}
\hline \multicolumn{1}{|c|}{ Categoria } & \multicolumn{1}{c|}{ Aspectos abordados } \\
\hline Territórios & $\begin{array}{l}\text { Refere-se aos assuntos relativos a territórios, localidades e, } \\
\text { espaços deconvivência comunitária. }\end{array}$ \\
\hline Sujeitos e Saberes & $\begin{array}{l}\text { Refere-se aos aspectos relacionados aos saberes das pessoas } \\
\text { de uma forma geral, pessoas das comunidades, profissionais e } \\
\text { os saberes advindos deles. }\end{array}$ \\
\hline $\begin{array}{ll}\text { Dimensões } \\
\text { cuidado }\end{array}$ & $\begin{array}{l}\text { do Diz respeito aos aspectos relacionados a produção de cuidado } \\
\text { em saúde. }\end{array}$ \\
\hline $\begin{array}{l}\text { Corpo } \\
\text { subjetividade }\end{array}$ & $\begin{array}{l}\text { eTrata de questões relacionais acerca dos aspectos físicos e } \\
\text { emocionais. }\end{array}$ \\
\hline $\begin{array}{l}\text { Política pública } \\
\text { a TCl como práticarelações entre si. }\end{array}$ & \\
\hline
\end{tabular}

Fonte: produzida pela autora.

\section{a) Territórios}

A participação da comunidade é inclusa na pauta dos programas governamentais, sobretudo em ações territoriais, as intervenções tornam-se mais 
efetivas, como apresentado nas narrativas sobre a experiência acadêmica na comunidade de Pirambu. A história nos remete ao MRSB, no qual os movimentos sociais lutavam por direitos, reivindicavam um modelo assistencial focado nas necessidades de saúde da população abrangendo os DSS e a importânciado debate sobre determinação social da saúde que propõe o caráter comunicativo entre o processo social e o biológico compreendendo a enfermidade no plano coletivo (VASCONCELOS e SCHMALLER, 2014; GALBOIS e DALBELLO-ARAUJO, 2017).

Consideramos que neste período descrito, embora a demanda dos moradores da comunidade fosse medicamentosa, o sofrimento referia-se a um intenso processo de segregação, desigualdades socioeconômicas e perda do sentimento de pertença. Como nos aponta Czeresnia (2009) sobre a importância da permeabilidade entre as perspectivas de prevenção e promoção da saúde, a experiência na comunidade mostrou que a implementação das ações de saúde deve ter uma compreensão mais abrangente estabelecendo articulações entreaspectos sociais, culturais, psicológicos e econômicos, medidas de controle e agravo de doençase parcerias governamentais e não governamentais (BUSS et al., 2020).

A TCl e a promoção da saúde abordam a importância do reconhecimento e mapeamento do território, pois é essencial tomar conhecimento sobre sua história, identificar os serviços e recursos disponíveis na localidade, a situação sócio econômica, profissional e escolaridade dos moradores, os problemas enfrentados pela comunidade e seus recursos culturais, dispensando uma concepção de assistência centrada no modelo biomédico que tende à medicalização massiva dos indivíduos. A figura 1 ilustra os recursos comunitários de um território, onde localizam-se escola, farmácia, igreja, centro espírita, creche, feira e pessoas participando dessesespaços, exercendo e expressando seus valores culturais: 
Figura 1: Exemplo de território e seus recursos comunitários.

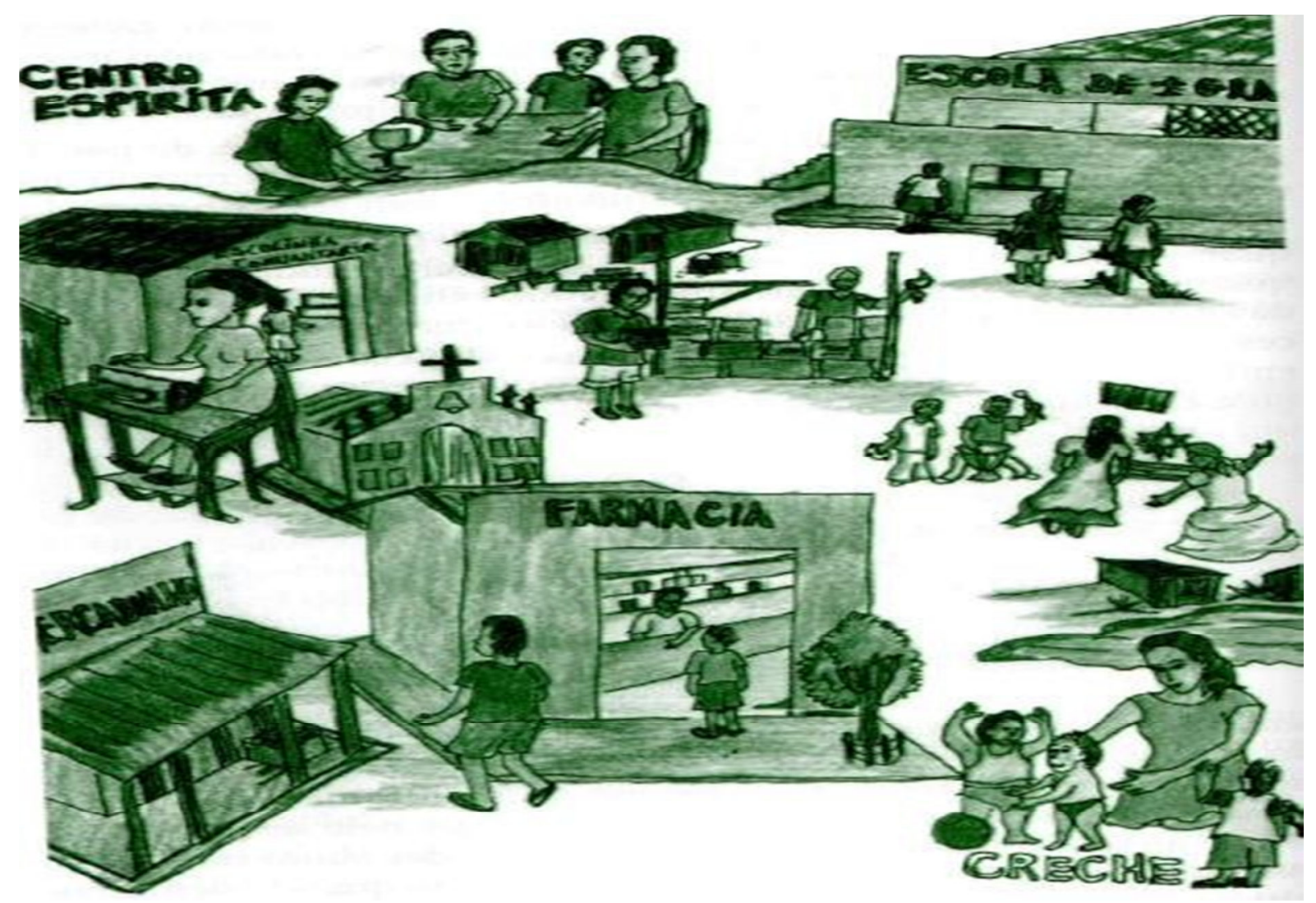

Fonte: BARRETO, 2010, pag. 182.

A relação entre o terapeuta comunitário e a comunidade obteve grande destaque no material analisado, enfatizando a importância da criação de vínculos e redes de apoio social, as articulações intersetoriais e as dimensões do autoconhecimento, cuidado de si e cuidado com o outro. A relação dialógica ocupa papel central nesse ponto, uma vez que o processo de comunicação entre terapeutas e comunidade norteia-se pelos princípios da horizontalidade e circularidade.

Assim, o aprendizado acontece de forma mútua, estimulando práticas problematizadoras e reflexivas que proporcionam uma compreensão cada vez mais ampla e crítica sobre o mundo, gerando um processo de reconhecimento e engajamento (FREIRE, 1970). 


\section{b) Sujeitos e saberes}

Nos materiais analisados há ênfase na ideia de convivência respeitosa entre o saber científico e o saber popular, com a integração e valorização das tradições culturais e as contribuições da ciência. A premissa adotada pela $\mathrm{TCl}$ está em concordância com a concepçãoholística de saúde abordada pela PNPS que assume uma postura de oposição à hegemonia biomédica (BARRETO, 2010, PNPS, 2007; VASCONCELOS e SCHMALLER, 2014).

O processo de transformação da realidade individual e coletiva passa pela corresponsabilidade através da comunhão entre os saberes, sejam eles adquiridos na família, escola, universidade, comunidade ou pela ancestralidade possibilitam o acesso a um repertóriode práticas de cuidado que pode contemplar inúmeras formas de produzir saúde, englobando tanto a sabedoria popular que trata de doenças por meio de ervas, plantas medicinais, benzimento como o conhecimento científico que utiliza medicamentos, exames, entre outros (Figura 2).

Figura 2: Exemplo de uma mulher que leva o filho em consulta dos saberes popular e tradicional.
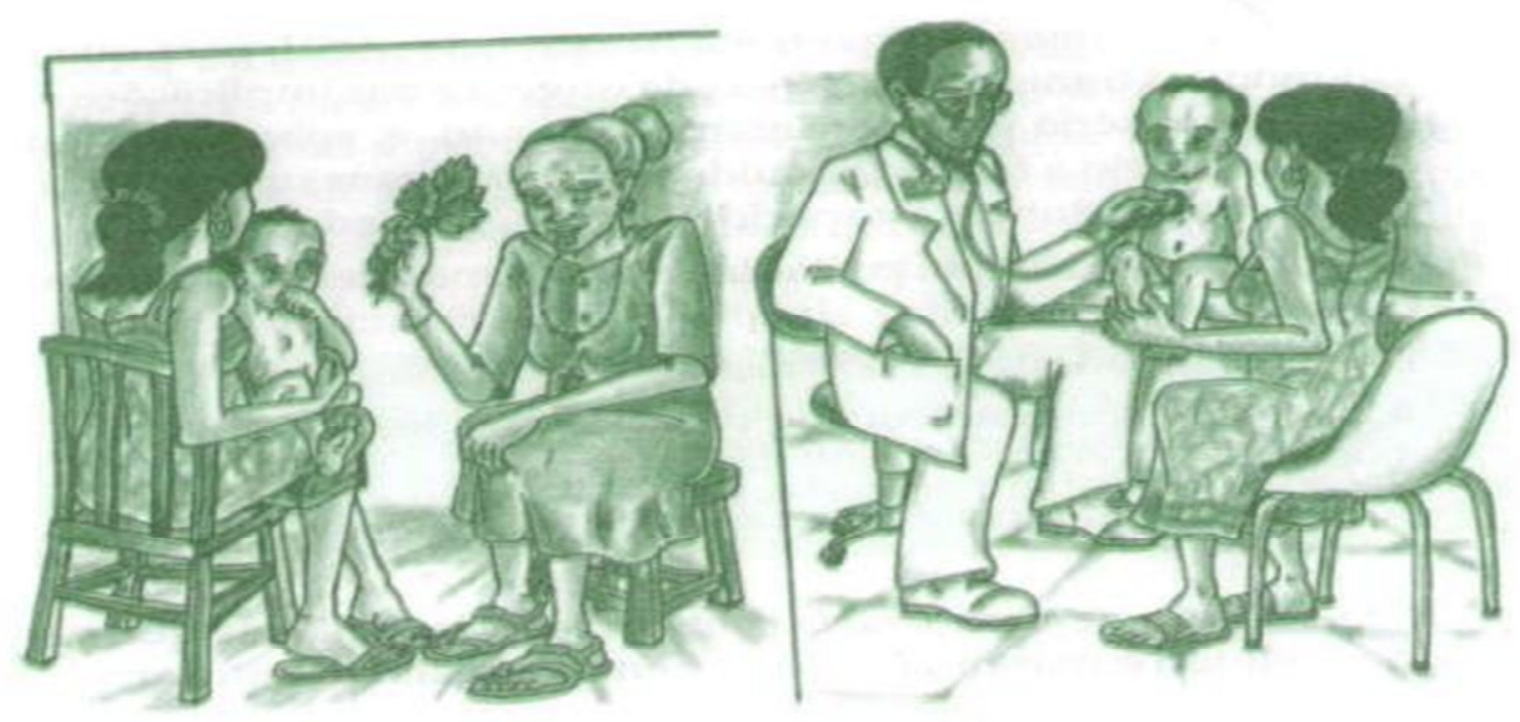

Fonte: BARRETO, 2010, pag. 36. 
Sob uma perspectiva transdisciplinar e transcultural, se propõe aos profissionais de saúde uma leitura sobre o simbolismo das narrativas e sua interlocução com o sistema de crenças e vivências socioculturais dos indivíduos (BARRETO, 2014). Para Alarcon, Vidal e Rozas (2003) a incorporação da percepção de todos envolvidos no processo saúde-doença, sejam profissionais e usuários, revela uma forma singular de explicá-lo, pois é fruto da história social e cultural de cada um.

\section{c) Dimensões do cuidado}

Nesta categoria há uma variedade de aspectos teóricos e metodológicos contemplados nos materiais que expressam diferentes formas de se produzir o cuidado em saúde, norteados pelo simbolismo e no emprego de técnicas lúdicovivenciais, com base na medicina tradicional chinesa. A investigação de uma enfermidade é atravessada por uma série de indagações que ampliam a percepção sobre o processo saúde-doença, trazendo à tona questões sociais, culturais, históricas e econômicas, cabendo ao profissional conscientizar-se que o sintoma é uma mensagem inconsciente com valor comunicativo que se expressa no corpo e precisa ser decodificada.

Reconhecer e cuidar de suas próprias dores lhes permitem aprender a lidar com as ressonâncias que ocorrem na relação que estabelecem com as pessoas que cuidam. Desta forma, a ética do cuidado sedimenta-se por meio de uma relação de compromisso pessoal (FOUCAULT, 2010; TAVARES, ROCHA e CASTRO, 2018). $\mathrm{Na}$ figura 3, temos um conto utilizado nos módulos de capacitação em TCl que aborda a resiliência, tema de destaque no material coletado. 
Figura 3: Fotografia de uma ostra com a pérola.

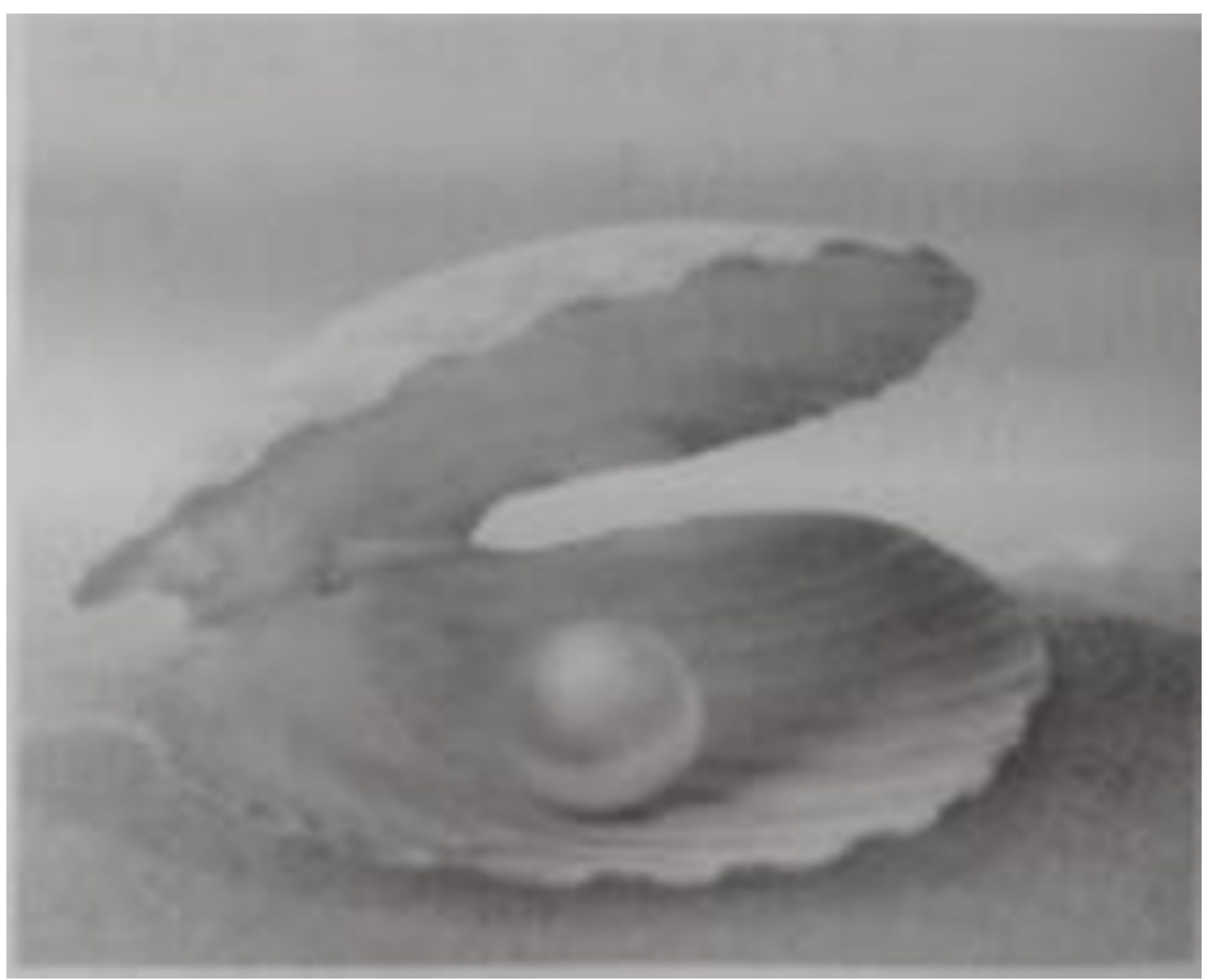

Fonte: Barreto, 2017; pág. 50.

"As pérolas são produtos da dor, resultado da entrada de uma substância estranha ou indesejável no interior da ostra, como um parasita ou um grão de areia. Na parte interna da concha é encontrada uma substância lustrosa chamada nácar. Quando um grão de areia a penetra, as células do nácar começam a trabalhar e cobrem o grão de areia com camadas e mais camadas, para proteger o corpo indefeso da ostra. Como resultado, uma linda pérola vai se formando, pois é uma ferida cicatrizada." (trecho extraído do livro Cuidando do cuidador - Técnicas e vivências para o resgate da autoestima). 
Nesse sentido, a ótica discutida nesse estudo, nos possibilitou compreender que a produção de cuidado também é geradora de incertezas, dúvidas e inquietação em função dos constantes movimentos de problematização como assinalado por Barros e Cesar (2018). Assim, posiciona-se sob uma perspectiva fenomenológica, ressignificando os modos de compreender e interpretar os fenômenos, respeitando a singularidade dos sujeitos, buscando através do diálogo subjetivar os acontecimentos manifestados em suas vidas.

Com a Teoria do Agir Comunicativo de Habermas (2012), podemos estabelecer uma comparação entre as esferas existentes na sociedade, o mundo da vida que diz respeito ao agir comunicativo, o simbólico, a rede de significados e o consenso proveniente do entendimento mútuo, permeada pela racionalidade comunicativa e, o sistema que se refere ao agir instrumental, pautada em uma lógica onde os fins justificam os meios. Desta forma, o sentido norteador de nossa discussão é fundamentado no diálogo, na integração entre objetividade e subjetividade, na tomada de consciência individual e coletiva visando a autonomia e o protagonismo dos sujeitos que tem como princípio ético a ação comunicativa, ou seja, a participação dos envolvidos na produção do cuidado em saúde.

\section{d) Corpo e subjetividade}

Identificamos um extenso conteúdo sobre a leitura simbólica de sintomas corporais, apresentando um diálogo entre partes do corpo humano e as mensagens inconscientes que nele se expressam. As perguntas relacionadas ao sintoma proporcionam um melhor entendimento sobre a situação vivida, traz informações sobre a existência de outros significados que precisamser investigados.

O processo comunicativo em questão mostra um modo interacional e intersubjetivo de estar com o outro, estabelecendo uma ação comunicativa viabilizada pelo diálogo entre sujeitos e profissionais de saúde mediada por uma linguagem simbólica que permite a apreensão e compreensão dos sujeitos acerca de seus próprios corpos. Nesse sentido, encaminha-se para a racionalidade 
comunicativa visando o consenso e o entendimento mútuo no que ser refere a tomada de decisão dos envolvidos (HABERMAS, 2012).

\section{e) Política pública e a $\mathrm{TCl}$ como prática}

Nessa categoria obtivemos informações sobre o planejamento organizacional e regulamentar e, o conteúdo programático do curso de $\mathrm{TCl}$. Esse estrutura-se a partir de uma dinâmica que propõe o entrelaçamento das teorias que fundamentam a prática (pensamento sistêmico, teoria da comunicação, antropologia cultural, pedagogia de Paulo Freire e resiliência) com exercícios e vivências terapêuticas.

Em nosso estudo emergiram duas concepções acerca do conteúdo curricular do curso. A primeira traz uma perspectiva fenomenológica, no sentido da captura do fenômeno "transformar-se em terapeuta comunitário", uma vez que esse processo passa pelo modo como o terapeuta em formação vive suas experiências, elabora suas questões. Nela o enfoque está naexperiencia subjetiva intermediada pelo social por meio de diversificadas formas de linguagem, sendo que no currículo com base fenomenológica a aprendizagem se dá a partir da própria experiência, no caso da TCI tanto o formador quanto o terapeuta em formação (SILVA, 1999). Entende-se que o formador em TCl torna-se um "parteiro", acompanha o processo gestacional e o nascimento da pessoa do terapeuta. Não se trata de um curso no qual um professor ministra um conteúdo, mas de uma formação que é um percurso, onde o formador atua construindo junto ao grupo conhecimento individual e coletivo, através de partilhas, vivências teórico-práticas.

A segunda diz respeito ao modo de sistematização do curso que consideramos alinhada aos pressupostos teórico-metodológicos da Espiral Construtivista (EC) que tem como características o diálogo, a aprendizagem interativa, o contexto e a cultura. Influenciada pela aprendizagem baseada em problemas (ABP) e nas metodologias ativas enfoca na construção do conhecimento por meio da problematização (LIMA, 2017). De acordo com os pressupostos daEC, 
encontramos similaridades com a formação em TCl que constrói-se nas seguintes etapas:

1) Identificando problemas: conhecimentos, temas, sentimentos e percepções são trabalhados apartir dos valores que os terapeutas em formação já possuem; 2) Formulando explicações: partilha de formas explicativas sobre os questões identificadas por eles; 3) Elaborando questões: construção coletiva e análise das questões para ampliação do entendimento e possíveis intervenções; 4) Buscando novas informações: estimulação do formador para a busca do conhecimento; 5) Construindo novos significados: produto dos saberes prévios e novos a partir do compartilhamento em grupo e; 6 ) feedback de autoavaliação e metacognição, como por exemplo nos momentos de apreciação e intervisão em $\mathrm{TCl}^{1}$.

Encontramos informações mais recentes sobre a TCl, abordando sobre sua inclusão como política pública através da PNPIC de 2017 e as recomendações do Ministério da Saúde para sua utilização como estratégia de saúde mental na atenção básica em material direcionado aos formadores. Os demais não apontaram esses dados, o que indica a necessidade de uma atualização dos materiais voltados para os terapeutas em formação. Além disso, as discussões sobre o processo saúdedoença, a determinação social da saúde e os DSS na formação em TCltornam-se fundamentais para estimular a capacidade crítica e reflexiva dos futuros terapeutas que atuarão para o fortalecimento e consolidação da prática no SUS.

\section{CONSIDERAÇÕES FINAIS}

Constatamos que os princípios e pressupostos teórico-metodológicos da $\mathrm{TCl}$ estão fortemente fundamentados na PNPS, legitimando-a como importante estratégia de intervenção psicossocial nos territórios e serviços de saúde, já que

\footnotetext{
${ }^{1}$ A intervisão refere-se ao momento de condução dos formadores na construção sistematizada do trabalho do terapeuta comunitário através da partilha de experiências vividas na prática cotidiana e de reflexão sobre si e seu papel como cidadão visando seu crescimento pessoal e profissional. $O$ posicionamento horizontal do formador propicia o aprendizado coletivo possibilitando a organização das ideias, sentimentos e dúvidas dos terapeutas. A apreciação é o momento de reflexão da equipe sobre seu desempenho na condução da roda de TCl, visando o aprimoramento (BARRETO, 2010).
} 
considera os indivíduos e coletividades como agentes de mudança nos processos de adoecimento e no enfrentamento de adversidades. Recomendamos a atualização do material destinado à formação, visto que diversos acontecimentos ocorreram nos últimos anos, como a inserção da TCI na PNPIC, o desmonte das políticas de atenção básica e saúde mental e, recentemente, a crise sanitária e humanitária causada pela pandemia do novo coronavírus.

Além disso, o trabalho em comunidades demanda um olhar diferenciado sobre os contextos de extrema vulnerabilidade social, onde as condições de vida, saúde e trabalho encontram-se em alto nível de precariedade e influenciam significativamente no comportamento e estado emocional dos indivíduos e coletividades, sendo necessária uma discussão mais efetiva sobre os DSS e a determinação social da saúde. Por fim, consideramos que a $\mathrm{TCl}$ e a promoção da saúde possuem laços de afinidade na tessitura de suas narrativas e práticas, pois apostam em perspectivas reflexivas e críticas para o cuidado em saúde dos indivíduos, comunidades e coletividades.

\section{REFERÊNCIAS BIBLIOGRÁFICAS}

ASSOCIAÇÃO BRASILEIRA DE TERAPIA COMUNITÁRIA. A ABRATECOM. Disponível em: https://www.abratecom.org.br. Acesso realizado em 03 jan. 2021.

ABRATECOM. Caderno Orientador $\mathbf{n}^{\circ} \mathbf{2}$ - Capacitação em Terapia Comunitária Integrativa e capacitação em Técnicas de Resgate da Autoestima - Cuidando do cuidador. Editora Itálico, 2019.

AGENDA. In: Michaelis Dicionário da Língua Portuguesa. São Paulo. Melhoramentos. Disponível em: https://michaelis.uol.com.br/busca?id=OWQE. Acesso em: 30 de jan. 2021.

ASSOCIAÇÃO BRASILEIRA DE TERAPIA COMUNITÁRIA. A ABRATECOM. Disponível em: https://www.abratecom.org.br. Acesso realizado em 25 nov. 2020.

ALARCON, A. M.M.; VIDAL, A. H.; ROZAS, J. N. Salud intercultural: elementos para la construcción de sus bases conceptuales. Revista Médica do Chile 2003, Temuco, v.131, n. 9, p. 1061-1065, set. 2003. Disponível em: https://scielo.conicyt.cl/pdf/rmc/v131n9/art14.pdf. Acesso em: 27 out. 2020.

BARRETO, A. P. Terapia Comunitária passo a passo. 4. ed. Fortaleza: Gráfica LCR, 2010. $408 p$.

BARRETO, A. P. Cuidando do cuidador: Técnicas e vivências para o resgate da autoestima. Fortaleza: Gráfica LCR, 2017. 228 p. 
BARRETO, A. P. Quando a boca cala os órgãos falam... desvendando as mensagens dos sintomas. 2. ed. Fortaleza: Gráfica LCR, 2014. 400 p.

\section{BARRETO, A. P. A fala do sintoma: desvende a mensagem dos sintomas. Fortaleza: Gráfica} LCR, 2019. $136 \mathrm{p}$.

BARROS, M. E. B de; CESAR, J.M. A saúde em práticas de cuidado: dialogia e cogestão. (2018). In: Sá, M. C (org) Organização do cuidado e práticas de saúde: abordagens, pesquisa e experiências em ensino [livro eletrônico]. Rio de Janeiro: Editora Fiocruz, 2018.

BUSS, P. M. et al. Promoção da saúde e qualidade de vida: uma perspectiva histórica ao longo dos últimos 40 anos (1980-2020). Rev. Ciênc. Saúde Coletiva [online] 2020, Rio de Janeiro, vol. 25, n.12, p. 4723-4735, dez 2020. Disponível em https://www.scielo.br/pdf/csc/v25n12/1413-8123-csc-25-12-4723.pdf. Acesso em 04 jan. 2021.

BRASIL. Ministério da Saúde. Declaração de Santa Fé de Bogotá. Promoção da Saúde: Cartas de Ottawa, Adelaide, Sundsvall e Santa Fé de Bogotá. Brasília: MS, Fiocruz; 1996. p. 41-47. Disponível em: https://bvsms.saude.gov.br/bvs/publicacoes/cartas_promocao.pdf. Acesso em 4 jan. 2021.

BRASIL. Ministério da Saúde. Política Nacional de Práticas integrativas e complementares. PORTARIA N 849, DE 27 DE MARÇO DE 2017.

BRASIL. Ministério da Saúde. Secretaria de Vigilância em Saúde. Secretaria de Atenção à Saúde. Política Nacional de Promoção da Saúde: PNPS: Anexo I da Portaria de Consolidação $\mathrm{n}^{\circ} 2$, de 28 de setembro de 2017, que consolida as normas sobre as políticas nacionais de saúde do SUS/ Ministério da Saúde, Secretaria de Vigilância em Saúde, Secretaria de Atenção à Saúde. - Brasília: Ministério da Saúde, 2018. Acesso em: 25 nov 2020.

CARTILHA. In: Michaelis Dicionário da Língua Portuguesa. São Paulo. Melhoramentos. Disponível em: https://michaelis.uol.com.br/busca?id=OWQE. Acesso em: 30 de jan. 2021.

CZERESNIA, D. O conceito de saúde e a diferença entre prevenção e promoção. In: Czeresnia, D.; Freitas, C. M (orgs). Promoção da Saúde: conceitos, reflexões e tendências [online]. Rio de Janeiro: Editora Fiocruz, 2009.

CORREIA, M.V.C.; MEDEIROS, S.M.A. As bases da Promoção da Saúde nas Conferências Internacionais e a Reforma Sanitária Brasileira: concepção do processo saúde e doença em questão. In: Vasconcelos, K.E.L.; Costa, M.D.H (orgs). Por uma crítica da Promoção da Saúde: contradições e potencialidades no contexto do SUS. São Paulo: Editora Hucitec, 2014.

GARBOIS, J. A.; SODRÉ, F.; DALBELLO-ARAUJO, M. Da noção de determinação social àde determinantes sociais da saúde. Rev. Saúde e Debate [online] 2017, Rio de Janeiro, vol. 41, n.112, p. 63-76, jan-mar 2017. Disponível em https://www.scielo.br/pdf/sdeb/v41n112/01031104-sdeb-41-112-0063.pdf. Acesso em 25 de jan. 2021.

GIFFONI, F. A. O. Saber ser, saber fazer: Terapia comunitária, uma experiência de aprendizagem e construção da autonomia. 2008. 235p. Tese (Doutorado em Educação) Faculdade de Educação, Universidade Federal do Ceará, Fortaleza, 2008.

GOMES, D. O. A expansão da Terapia Comunitária Integrativa no Brasil e sua inserção nas políticas públicas nacionais. 2013. 154p. Dissertação (Mestrado em Saúde da Família) Programa de Pós-Graduação em Saúde da Família. Universidade Federal do Ceará, Sobral CE, 2013.

FOUCAULT, M. A hermenêutica do sujeito. 2. ed. São Paulo: WMF Martins Fontes, 2010. FREIRE, P. Pedagogia do Oprimido. 17a. ed. Rio de Janeiro: Paz e Terra, 1987. 
HABERMAS. J. Teoria do agir comunicativo: racionalidade da ação e racionalização social. 3. ed. São Paulo: Martins Fontes, 2012.

LIMA, V.V. Espiral Construtivista: uma metodologia ativa de ensino-aprendizagem. Rev. Interface [online], Botucatu, v. 21, n. 61, p. 421- 434, 2017. Disponível em: https://www.scielo.br/pdf/icse/v21n61/1807-5762-icse-1807-576220160316.pdf. Acesso em 25 nov. 2020.

LIVRO. In: Michaelis Dicionário da Língua Portuguesa. São Paulo. Melhoramentos. Disponível em: https://michaelis.uol.com.br/busca?id=OWQE. Acesso em: 30 de jan. 2021.

MORAES, R.; GALIAZZI, M. do C. Análise textual discursiva. 3. ed. ljuí: Editora Unijuí, 2016.

MOYSÉS, N. M. N.; TAVARES, M. de F. L; GUIMARAES, T. C., VIEIRA, A. L. S.; CARDOSO, A. L. Qualificação da gestão do Sistema Único de Saúde: a especialização dos gestores do trabalho e da educação no contexto do cuidado. In: Sá, M. C (org) Organização do cuidado e práticas de saúde: abordagens, pesquisa e experiências em ensino [livro eletrônico]. Rio de Janeiro: Editora Fiocruz, 2018.

ROCHA, P. R.; DAVID, H. M. S. L. Determinação social ou determinantes? Uma discussão com base na Teoria da Produção Saúde da Saúde. Rev. Esc Enferm USP [online] 2015, São Paulo, vol 49, n.1, p. 129-135, fev 2015. Disponível em https://www.scielo.br/pdf/reeusp/v49n1/pt_0080-6234-reeusp-49-01-0129.pdf. Acesso em 25 de jan. 2021.

SILVA, T. T. da. Documentos de identidade: uma introdução às teorias do currículo. $2^{\mathrm{a}}$. ed. Belo Horizonte: Editora Autêntica, 1999.

SOUZA, J. de; KANTORSKI, L. P.; VILLAR LUIS, M. A. Análise documental e observação participante na pesquisa em saúde mental. Revista Baiana de Enfermagem, Salvador, v. 25, n. 2, p. 221-228, maio/ago. 2011. Disponível em: https://aratuipe.ufba.br/index.php/enfermagem/article/view/5252/4469. Acesso realizado em 16 jan. 2021.

TAVARES, M. de F. L.; ROCHA, R. M da; CASTRO, A. M. de. O cuidado: uma reflexão crítica à luz dos princípios e valores da promoção da saúde. In: Sá, M. C (org) Organização docuidado e práticas de saúde: abordagens, pesquisa e experiências em ensino [livro eletrônico]. Rio de Janeiro: Editora Fiocruz, 2018.

VASCONCELOS, K.E.L.; SCHMALLER, V.P.V. Promoção da Saúde: Polissemias conceituais e ideopolíticas. In: VASCONCELOS, K.E.L.; COSTA, M.D.H (org). Por uma crítica da Promoção da Saúde: contradições e potencialidades no contexto do SUS. São Paulo: Editora Hucitec, 2014. 